\title{
Modificação da composição química de farinhas integrais de grãos de amaranto após a aplicação de diferentes tratamentos térmicos
}

\author{
Changes in chemical composition of whole flours from grains amaranth a \\ fter different thermal treatments
}

\author{
Maria das Graças de Assis Bianchini ${ }^{I}$ Adelaide Del Pino Beleia ${ }^{\mathrm{II}}$ Aloisio Bianchini ${ }^{\mathrm{III}}$
}

\section{RESUMO}

O emprego do calor é uma alternativa utilizada com a finalidade de garantir a inocuidade, melhorar características sensoriais e aumentar a digestibilidade dos vegetais, tornandoos aptos ao consumo de crianças. No entanto, condições severas de calor podem alterar a sua composição nutricional. $O$ objetivo deste trabalho foi avaliar o efeito do calor seco ou úmido, antes da moagem, na composição química de farinhas integrais de grãos de amaranto (Amaranthus cruentus). As farinhas foram produzidas de grãos integrais in natura (FIAI), tostados (FIAT), cozidos e secos (FIAC) e pipocados (FIAP). Os tratamentos térmicos aplicados aos grãos não afetaram os teores de minerais das farinhas, com exceção do $\mathrm{Ca}$ e $\mathrm{Cu}$, mas elevaram os teores de lipídios (12 a 19\%) e de fibra solúvel (18 a 35\%) e reduziram de fibra insolúvel (5,8 a 8,5\%) em comparação com à in natura. Os aminoácidos sulfurados foram os primeiros limitantes na FIAI, para idades de 1 a 10 anos e o pipocamento reduziu a qualidade aminoacídica do grão, que passou a ser limitante, também, em lisina para todas as idades. A tostagem e a cocção melhoraram o balanço aminoacídico das farinhas e os aminoácidos sulfurados deixaram de ser limitantes para maiores de três anos.

Palavras-chave: pipocamento, cozimento, tostagem, escore químico.

\section{ABSTRACT}

The use of heat is an alternative to ensure the safety, improve sensory characteristics and increase digestibility of vegetables, making them suitable for children consumption. However, severe heat conditions may alter its nutritional composition. The objective of this study was to evaluate the effect of dry or humid heat before milling in chemical composition of whole amaranth (Amaranthus cruentus) grain flours. The flours were produced from in nature whole grains (UGF), toasted (PGF), cooking and dried (CDF) and popping (PGF). The heat treatments applied to grains did not affect the mineral contents of the flour, with the exception of $\mathrm{Cu}$ and $\mathrm{Ca}$. However, the treatment elevated the levels of lipids (12-19\%) and soluble fiber (18-35\%) and reduced the insoluble fiber (5.8-8.5\%) of the flour when compared to in nature. The sulfur amino acids were first limiting in UGF, for 1-10 years old and the popping reduced the quality of the amino acids which has become limiting, too, in lysine, for all ages. The toasting and cooking improved the balance of amino acids of flours obtained and the sulfur amino acids ceased to be the limiting for children over three years.

Key words: popping, cooking, toasting, chemical score.

\section{INTRODUÇÃO}

O Brasil apresenta graves e flagrantes problemas decorrentes da inadequação de consumo de alimentos, se de um lado ocorre manutenção do quadro de morbimortalidade infantil devido às doenças infectocontagiosas e desnutrição, do outro lado há o aumento da prevalência de doenças crônicas não transmissíveis e da obesidade (COLUCCI, 2010). A obtenção de alimentos e matérias-primas, para a produção de alimentos, que forneçam componentes nutricionais de forma equilibrada constitui um desafio para a ciência e a tecnologia. A publicação da Food and Drug Administration lista uma série de grãos de vegetais como o painço, a cevada, o arroz, o centeio, a aveia e o milho, como cereais, e a quinoa e o amaranto, como pseudocereais, entre outros, que podem ser utilizados de forma integral na alimentação humana (USA, 2006). O amaranto (Amaranthus sp) é classificado como pseudocereal,

IFaculdade de Nutrição, Universidade Federal de Mato Grosso (UFMT), Av. Fernando Correa da costa, 2367, 78060-900, Cuiabá, MT, Brasil. E-mail: magra@ufmt.br. Autor para correspondência.

IIDepartamento de Ciência e Tecnologia de Alimentos, Universidade Estadual de Londrina (UEL), Londrina, PR, Brasil.

IIIFaculdade de Agronomia, Medicina Veterinária e Zootecnia, UFMT, Cuiabá, MT, Brasil. 
devido às suas características botânicas e nutricionais, pertence à família Amaranthaceae, classe das dicotiledôneas, apresenta inflorescência tipo panícula e é uma excelente fonte de nutrientes. O interesse no seu aprimoramento é reconhecido por organismos internacionais. No entanto, a sua incorporação à alimentação humana, segundo AMAYA-FARFAN et al. (2005), depende da criação de produtos que tenham aceitabilidade geral. A composição química e valor nutritivo do amaranto já têm sido estudados e podem variar com a espécie, sazonalidade, condições do meio ambiente e tratamentos agronômicos aplicados no cultivo da semente (SPEHAR et al., 2003). O conteúdo proteico é de alta qualidade biológica, devido ao alto teor de aminoácidos essenciais, em particular, a lisina, podendo assim ser um complemento para proteínas de arroz, milho, trigo (RODAS \& BRESSANI, 2009). Vários são os pesquisadores que há anos envidam esforços em prol da produção e consumo do amaranto no combate à desnutrição. Estudos recentes, no Quênia, mostraram o potencial de utilização do amaranto na complementação da alimentação de grupos vulneráveis, principalmente as crianças (MBURU et al., 2011). Uma das formas mais práticas para o consumo de amaranto, além do grão inteiro, é a farinha integral, que pode ser empregada como ingrediente na indústria ou diretamente pela população para enriquecer a sua alimentação. O tratamento térmico é uma alternativa utilizada para produtos de origem vegetal, com a finalidade de garantir não só sua inocuidade, como também melhorar suas características sensoriais e aumentar a sua digestibilidade. No entanto, submeter alimentos a condições severas de calor pode causar efeito inverso com perda de seu valor nutricional. Conforme CAPRILES et al. (2008), o tratamento utilizado no processamento do amaranto, antes do consumo do grão, pode modificar sua composição química. Assim, este trabalho foi desenvolvido com o objetivo de avaliar a variação na composição química de farinhas integrais produzidas a partir de grãos de amaranto tratados por meio de calor seco ou úmido.

\section{MATERIAL E MÉTODOS}

Os grãos de Amaranthus cruentus L. utilizados para a produção das farinhas foram da variedade BRS Alegria, provenientes do município de Sorriso-MT, Brasil. Inicialmente, os grãos in natura foram limpos com auxílio de ventilação, para remoção de resíduos de palhas e padronizados em peneira de 20 mesh (abertura de $0,85 \mathrm{~mm}$ ), quando os grãos mal formados foram removidos. A partir dos grãos padronizados (umidade de $\pm 11,5 \%$ ), foram elaboradas quatro diferentes farinhas pela moagem dos grãos em moinho de rotor (Fritsch/Alemanha), com peneira de malha $0,5 \mathrm{~mm}$, na rotação de 12.000 rpm. A primeira farinha foi obtida dos grãos crus, denominada de farinha integral de grãos de amaranto in natura (FIAI), e as outras três, de grãos tratados termicamente. A farinha integral de grãos de amaranto cozidos (FIAC) foi obtida a partir do cozimento dos grãos, sob ebulição $\left(98^{\circ} \mathrm{C}\right)$, em fogão a gás (Fischer/ Brasil), utilizando três partes de água para cada parte de grãos, em recipiente tampado, sem adição de óleo e temperos e por aproximadamente 10 minutos, em chama moderada. Ao final do processo, não restava mais água e os grãos apresentavam-se macios e translúcidos. A gelatinização completa do amido foi verificada por meio da pressão dos grãos entre placas de vidro transparente, conforme técnica descrita em BASSINELLO et al. (2004). Após a cocção, os grãos foram secos a $50^{\circ} \mathrm{C} \pm 2^{\circ} \mathrm{C}$ por 16 horas em estufa com circulação de ar forçado (Fanen/São Paulo), conforme GAMEL et al. (2006); a farinha integral de grãos de amaranto pipocados (FIAP), por sua vez, foi obtida a partir de pipocas de grãos de amaranto, em condições de processamento estabelecidas por BIANCHINI \& BELEIA (2010). A última farinha foi obtida de grãos tostados (FIAT) em um equipamento composto por uma resistência elétrica de $1600 \mathrm{~W}$ e um controlador eletrônico de temperatura. A resistência aqueceu uma chapa de alumínio $(24 \mathrm{~cm} \times 33 \mathrm{~cm})$, à temperatura de $150^{\circ} \mathrm{C} \pm 5^{\circ} \mathrm{C}$, sobre a qual foram colocados, em cada batelada, em torno de $10 \mathrm{~g}$ de grãos para tostar. Os grãos foram mantidos sobre a chapa e agitados constantemente, por tempo de, aproximadamente, sessenta segundos. Em seguida, foram retirados e resfriados à temperatura ambiente $\left( \pm 30^{\circ} \mathrm{C}\right)$. As diferentes farinhas foram armazenadas em refrigerador doméstico (Consul), entre $4^{\circ} \mathrm{C}$ e $8^{\circ} \mathrm{C}$, em sacos de polietileno.

\section{Análises químicas}

O teor de umidade foi determinado pelo método $\mathrm{n}^{\mathrm{o}}$ 012/IV do IAL (2005). Os teores de cinzas lipídios e proteínas $(\mathrm{N}$ x 5,85) foram determinados de acordo com as metodologias da AOAC (1998) no 923-03, 920-39 e 960-52, respectivamente. As fibras insolúveis e solúveis foram determinadas pelo método 32-07 da AACC (1999), utilizando as enzimas $\alpha$-amilase termorresistente, protease e amiloglucosidase (Sigma, Sigma-Aldrich, St Louis). Os carboidratos foram estimados por diferença, considerando-se os teores de umidade, cinzas, proteínas e lipídios. Foram feitas triplicatas de cada 
análise. Os teores de cálcio, zinco, magnésio, ferro e de cobre foram determinados, em triplicatas, por espectrometria de emissão atômica com indução de plasma (EEA - ICP simultâneo, Thermo Jarrell Ash, ICAP 61E) (SILVA, 1999). A composição de aminoácidos foi realizada sem replicata, com base no procedimento adaptado dos métodos de WHITE et al. (1986) e HAGEN et al. (1989), por cromatografia líquida de alto desempenho com coluna de fase reversa. O triptofano foi determinado usando o método enzimático - espectrofotométrico de SPIES (1967). $\mathrm{O}$ escore químico (EQ) foi calculado com base nas necessidades de aminoácidos essenciais estabelecidos pela WHO/FAO (2007) para todas as faixas etárias. $\mathrm{O}$ experimento seguiu delineamento inteiramente casualizado, com quatro tratamentos (farinhas) e quatro repetições para todos os elementos analisados, com exceção da composição de aminoácidos e EQ. Os resultados obtidos foram submetidos à análise de variância e as médias dos tratamentos comparadas pelo teste de Tukey a 5\% de probabilidade de erro, utilizando-se do aplicativo Minitab 13.1 versão Trial (Minitab Inc., 2005).

\section{RESULTADOS E DISCUSSÃO}

Composição química das farinhas

A farinha de grãos in natura (FIAI) apresentou valores de proteínas, lipídios e fibras alimentares (Tabela 1) semelhantes às encontradas na literatura, como 14,0 a $16,6 \%$, para proteínas, 6,80 a $8,77 \%$, para lipídios, e 8,83 a $14,80 \%$, para fibras totais (CAPRILES et al., 2008; GAMEL et al., 2006). Alteração da composição centesimal, em função de tratamentos térmicos, para amaranto, é tema controverso. As condições de processamento utilizadas, envolvendo tipo de calor, temperatura e tempo provocaram alterações nos conteúdos de proteínas, lipídios e carboidratos, bem como nas frações da fibra. GAMEL et al. (2004 e 2006) também verificaram alterações nos grãos de Amaranthus cruentus submetidos a tratamentos térmicos, com redução de 6 a $8 \%$ de proteínas de grãos cozidos e de 2 a $4 \%$ de lipídios de grão pipocados.

A alta temperatura para pipocamento dos grãos afetou a fração proteica da FIAP, resultando em perda significativa de matéria proteica (2\%), comparada a FIAI (Tabela 1). Segundo SEGURA \& BRESSANI (2002), em torno de $65 \%$ das proteínas, está distribuída no germe e na casca do grão e apenas $35 \%$ se encontra no perisperma. Isso explica a perda de material proteico da FIAP, pois houve desprendimento de partes do gérmen e da casca durante o pipocamento. Por outro lado, os teores de lipídios encontrados nas FIAP, FIAC e FIAT foram superiores ao encontrado na FIAI. Os grãos de amaranto, de acordo com IRVING et al. (1981), contêm lipídeos na forma complexada em sua matriz embrionária, o que dificultou sua extração na FIAI.

$\mathrm{O}$ teor de carboidratos foi influenciado pela variação dos teores de proteínas e lipídios. Proporcionalmente, ocorreu uma redução no teor de carboidratos das farinhas de grãos tratados

Tabela 1 - Composição química por $100 \mathrm{~g}$ de farinhas de grãos Amaranthus cruentus ${ }^{1}$.

\begin{tabular}{|c|c|c|c|c|}
\hline \multirow{2}{*}{ Nutrientes } & \multirow[b]{2}{*}{ FIAI } & \multirow[b]{2}{*}{ FIAC } & \multirow[b]{2}{*}{ FIAT } & \multirow[b]{2}{*}{ FIAP } \\
\hline & & & & \\
\hline Proteínas (g) & $14,53 \pm 0,03 a$ & $14,62 \pm 0,12 \mathrm{a}$ & $14,63 \pm 0,06 a$ & $14,36 \pm 0,05 b$ \\
\hline Lipídios (g) & $6,46 \pm 0,10 \mathrm{c}$ & $7,62 \pm 0,06 \mathrm{a}$ & $7,71 \pm 0,05 \mathrm{a}$ & $7,26 \pm 0,12 b$ \\
\hline Carboidratos (g) & $76,81 \pm 0,17 \mathrm{a}$ & $75,67 \pm 0,20 \mathrm{c}$ & $75,46 \pm 0,09 c$ & $76,17 \pm 0,25 b$ \\
\hline Cinzas (g) & $2,19 \pm 0,09 a$ & $2,09 \pm 0,08 \mathrm{a}$ & $2,20 \pm 0,04 \mathrm{a}$ & $2,21 \pm 0,04 \mathrm{a}$ \\
\hline Fibra total (g) & $9,37 \pm 0,14 \mathrm{a}$ & $9,13 \pm 0,17 \mathrm{a}$ & $9,13 \pm 0,07 \mathrm{a}$ & $9,17 \pm 0,06 \mathrm{a}$ \\
\hline Fibra Insolúvel (g) & $8,10 \pm 0,13 a$ & $7,63 \pm 0,19 b$ & $7,41 \pm 0,04 b$ & $7,56 \pm 0,08 b$ \\
\hline Fibra Solúvel (g) & $1,27 \pm 0,04 \mathrm{c}$ & $1,50 \pm 0,02 b$ & $1,72 \pm 0,04 a$ & $1,61 \pm 0,05 \mathrm{ab}$ \\
\hline $\mathrm{Ca}(\mathrm{mg})$ & $0,13 \pm 0,002 b$ & $0,13 \pm 0,002 b$ & $0,13 \pm 0,003 \mathrm{a}$ & $0,13 \pm 0,001 b$ \\
\hline $\mathrm{Mg}(\mathrm{mg})$ & $0,19 \pm 0,001 \mathrm{a}$ & $0,20 \pm 0,001 \mathrm{a}$ & $0,20 \pm 0,006 \mathrm{a}$ & $0,20 \pm 0,005 \mathrm{a}$ \\
\hline $\mathrm{Cu}(\mathrm{mg})$ & $0,30 \pm 0,015 b$ & $0,31 \pm 0,010 \mathrm{~b}$ & $0,31 \pm 0,020 \mathrm{~b}$ & $0,34 \pm 0,006 \mathrm{a}$ \\
\hline $\mathrm{Zn}(\mathrm{mg})$ & $2,89 \pm 0,105 \mathrm{a}$ & $2,92 \pm 0,055 \mathrm{a}$ & $2,92 \pm 0,035 \mathrm{a}$ & $2,91 \pm 0,070 \mathrm{a}$ \\
\hline $\mathrm{Fe}(\mathrm{mg})$ & $7,51 \pm 0,279 \mathrm{a}$ & $7,47 \pm 0,220 \mathrm{a}$ & $7,75 \pm 0,170 \mathrm{a}$ & $7,82 \pm 0,170 \mathrm{a}$ \\
\hline
\end{tabular}

${ }^{1}$ Médias seguidas da mesma letra na linha não diferem estatisticamente entre si pelo teste de Tukey, a 5\% de probabilidade. Média dos dados em base seca \pm desvio padrão de quatro repetições.

FIAI - farinha integral de grãos de amaranto in natura; FIAC - farinha integral de grãos de amaranto cozidos; FIAT - farinha integral de grãos de amaranto tostados; FIAP - farinha integral de grãos de amaranto pipocados. 
termicamente em relação ao do grão in natura. Os tratamentos térmicos provocaram, ainda, redução no conteúdo de fibras insolúveis, com maior redução para tostagem $(8,5 \%)$ e menor para o cozimento $(5,8 \%)$. Por outro lado, houve acréscimo de fibras solúveis, em relação a FIAI (Tabela 1), sendo que a tosta provocou aumento da fração de fibra solúvel $(35,4 \%)$ superior ao do pipocamento $(26,8 \%)$ e do cozimento $(18,1 \%)$. Segundo REPO-CARRASCO-VALENCIA et al. (2009), altas temperaturas $\left(180^{\circ} \mathrm{C}\right)$ podem quebrar ligações glicosídicas das cadeias de polissacarídeos da parede celular em partículas mais solúveis. A quantidade de fibra total encontrada nas farinhas, no entanto, não sofreu alteração com os tratamentos térmicos, demonstrando que não houve perda de fibra do alimento, e sim uma alteração na sua característica, tornando-a mais solúvel. Em estudos desenvolvidos por CAPRILES et al. (2008) e GAMEL et al. (2004 e 2006), também não foram encontradas diferenças significativas entre os teores de fibras alimentares de grãos de A. cruentus submetidos a tratamentos térmicos. A proporção entre as frações de fibras, insolúvel e solúvel, encontradas por SCHNETZLER \& BREENE (1994) foi de 6:1 para o amaranto in natura, valor próximo ao encontrado neste trabalho para a FIAI, que foi de 6,4:1. A farinha que apresentou a menor relação entre fibras insolúveis e solúveis, de 4,3:1, foi a FIAT.

Os tratamentos térmicos utilizados não afetaram significativamente os conteúdos de cinzas e dos minerais magnésio, zinco e ferro das farinhas integrais de grãos de amaranto (Tabela 1), pois os valores desses minerais não diferiram estatisticamente da FIAI. O cobre e o cálcio foram os únicos elementos que apresentaram teores em níveis alterados, com um acréscimo do cobre na FIAP $(15,4 \%)$ e do cálcio na FIAT $(3,1 \%)$, em comparação com a FIAI. No caso do cobre, a alteração observada foi causada, provavelmente, pelo processo de tamisamento das pipocas para eliminação dos grãos não pipocados, feito em tamis de liga de cobre, quando as pipocas ainda estavam quentes. Esse acréscimo indesejável no conteúdo de cobre da FIAP pode ser facilmente eliminado no processo industrial pela substituição do tamis de cobre pelo de aço inoxidável. De qualquer modo, os valores encontrados estão inferiores ao

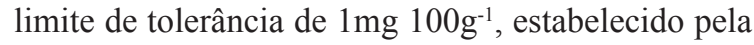
Portaria no 685, de 27/8/1998 do Ministério da Saúde (BRASIL, 1998).

No caso do cálcio não houve uma causa aparente para o aumento na FIAP. Os valores de minerais encontrados na FIAI foram inferiores aos encontrados por FERREIRA et al. (2007) e por
GAMEL et al. (2006). Essas diferenças podem ser devido ao solo, à época do ano e às condições de plantio do amaranto, pois, segundo WALTER et al. (2008), o conteúdo mineral é grandemente influenciado pelas condições de cultivo, incluindo fertilização e condições do solo, e pelo processamento.

De acordo com a ANVISA, RDC nº 269, de 22 de setembro de 2005 (BRASIL, 2005), o consumo diário de $50 \mathrm{~g}$ de uma das farinhas produzidas supre as necessidades dos minerais zinco, cobre e cálcio, de crianças de 1 a 3 anos em, aproximadamente, 35\%, $43 \%$ e $13 \%$, respectivamente. Para a faixa etária de 4 a 6 anos, a mesma ingesta supre os referidos minerais em $28 \%, 34 \%$ e $11 \%$, respectivamente. No caso do ferro, $62,5 \%$ seriam atendidas na faixa etária de 1 a 6 anos e as necessidades de magnésio seriam atendidas na sua totalidade.

\section{Perfil aminoacídico das farinhas de amaranto}

Os tratamentos térmicos aplicados aos grãos in natura provocaram alterações na proporção de aminoácidos das farinhas de amaranto (Tabela 2), com destaque à lisina, ao triptofano e à histidina. $\mathrm{O}$ cozimento e posterior secagem dos grãos (FIAC), em relação ao grão in natura (FIAI), reduziram os teores dos aminoácidos triptofano $(8,0 \%)$ e treonina $(5,8 \%)$ e aumentou os teores $(3,4 \%)$ de aminoácidos sulfurados. A tostagem (FIAT), por sua vez, provocou redução de lisina $(6,6 \%)$ e acréscimo de aminoácidos sulfurados $(7,8 \%)$. O pipocamento foi o tratamento térmico que apresentou as maiores alterações no perfil aminoacídico, em relação à FIAI, destacandose a redução da lisina $(37,0 \%)$, provavelmente devido à utilização de altas temperaturas $\left(215^{\circ} \mathrm{C}\right.$ a $\left.220^{\circ} \mathrm{C}\right)$ na produção das pipocas. GAMEL et al. (2004) relataram que o $\boldsymbol{A}$. cruentus pipocado apresentou maiores perdas de tirosina, cerca de $32,4 \%$, em relação ao in natura, seguido da fenilalanina $(19,8 \%)$ e da metionina (18,5\%). Os teores de aminoácidos sulfurados encontrados nas farinhas de amaranto variaram de 0,76 a $0,82 \mathrm{~g} 100 \mathrm{~g}^{-1}$ para cisteina e de

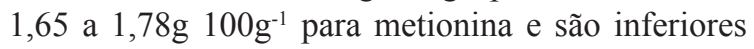
aos encontrados por MENDONÇA et al. (2009), que foram de 2,0 a $2,2 \mathrm{~g} 100 \mathrm{~g}^{-1}$ e de 2,0 a $2,4 \mathrm{~g} 100 \mathrm{~g}^{-1}$, respectivamente. De acordo com BELCHIOR et al. (2010), os solos de cerrado apresentam deficiência generalizada de enxofre e isso pode explicar as variações entre os dados obtidos e os encontrados na literatura, pois conforme ROY et al. (2006), o enxofre participa de vários processos de desenvolvimento da planta, tais como síntese de aminoácidos cisteina, cistina e metionina, que são essenciais para a produção de proteínas. 
Tabela 2 - Perfil de aminoácidos essenciais ( $\mathrm{mg} \mathrm{g}^{-1}$ de proteína) das farinhas de grãos de Amaranthus cruentus e as recomendações da WHO/FAO para diferentes faixas etárias.

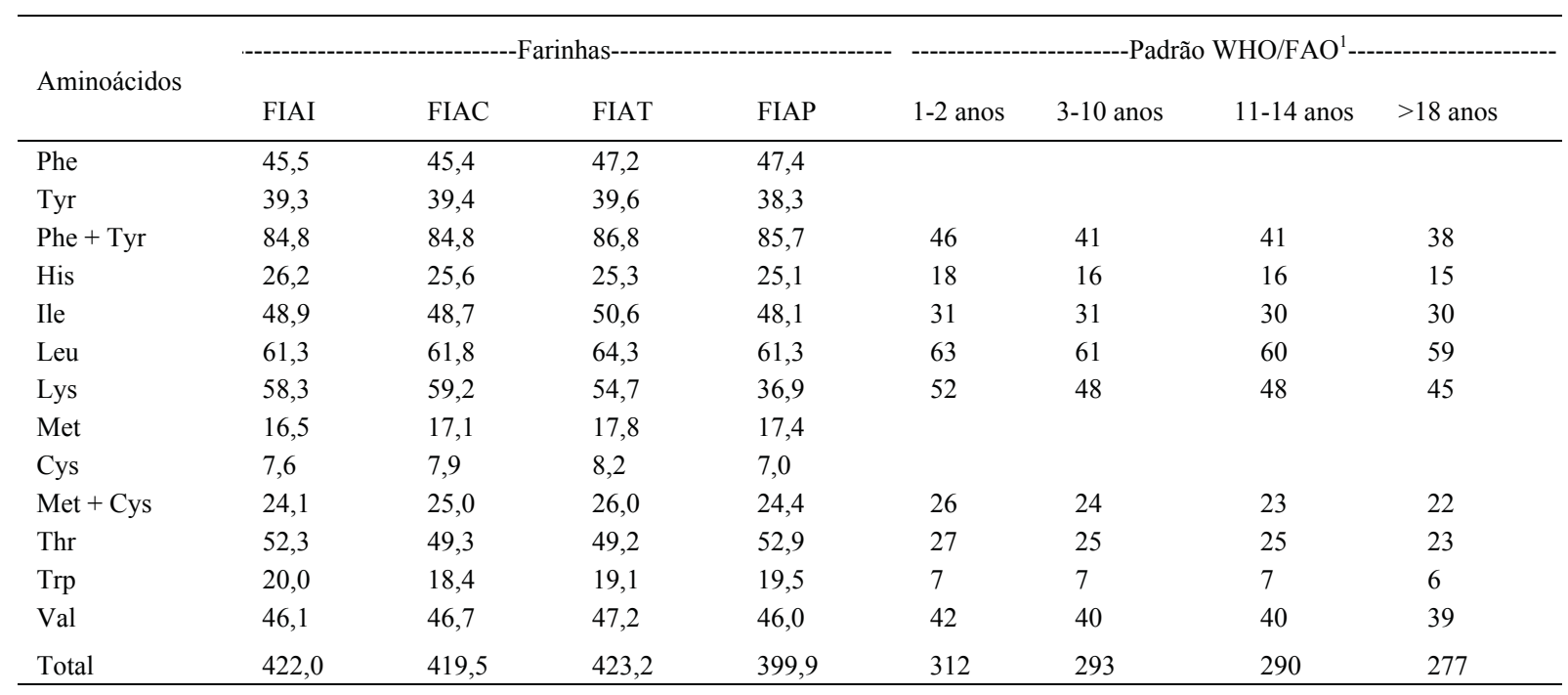

${ }^{1}$ WHO/FAO - World Health Organization/ Food and Agriculture Organization (2007).

FIAI - farinha integral de grãos de amaranto in natura; FIAC - farinha integral de grãos de amaranto cozidos; FIAT - farinha integral de grãos de amaranto tostados; FIAP - farinha integral de grãos de amaranto pipocados.

Na FIAI, os aminoácidos sulfurados, com escore químico de 0,93 a 1,00 (Tabela 3), foram os primeiros limitantes para a faixa etária de 1 a 10 anos, seguidos da leucina (escore de 0,97 a 1,00) para 1-2 anos. A demanda de aminoácidos essenciais para o adequado crescimento e desenvolvimento do indivíduo é maior na faixa etária de 1-2 anos, de acordo com a WHO/FAO (2007) e, no caso de escores químicos inferiores a 1,0, o aminoácido que apresentar o menor valor é considerado o "primeiro aminoácido limitante". Há, ainda, controvérsias sobre o primeiro aminoácido limitante do A. cruentus, uma vez que BEJOSANO \& CORKE (1998), estudando vários genótipos de $\boldsymbol{A}$. cruentus, verificaram que todos apresentaram alto conteúdo de lisina e aminoácidos sulfurados, sendo a leucina o primeiro limitante. GAMEL et al. (2004) encontraram para $\boldsymbol{A}$. cruentus a leucina como primeiro limitante, seguido da lisina.

Os tratamentos de cozimento e secagem e o de tostagem melhoraram o balanço aminoacídico da proteína do grão de amaranto, uma vez que os aminoácidos sulfurados e a leucina deixaram de ser limitantes na FIAC e FIAT, em relação à FIAI, para todas as faixas acima de 3 anos (Tabela 3). A proteína é considerada de alto valor nutricional se o escore químico de todos os aminoácidos essenciais for superior a 1,0. O pipocamento dos grãos, no entanto, afetou drasticamente o quantitativo de aminoácido lisina presente no grão in natura, passando a ser, na FIAP, limitante para todas as faixas etárias. O alto valor proteico do amaranto reside no balanço aminoacídico, com elevada concentração de aminoácidos essenciais, especialmente lisina e triptofano, que são limitantes na maioria das proteínas provenientes de cereais, bem como a treonina, o triptofano e a metionina, cujos teores são superiores aos encontrados na soja, que segundo VIEIRA et al. (1999) são de $38 \mathrm{mg} \mathrm{g}^{-1}, 15 \mathrm{mg}$ $\mathrm{g}^{-1}, 13 \mathrm{mg} \mathrm{g}^{-1}$, respectivamente.

Considerando a produção de alimentos para atender o público infantil, dentre as farinhas analisadas, a FIAC poderia ser utilizada na alimentação infantil de forma direta ou em preparações, considerando-se que houve a gelatinização completa do amido. A FIAI, por ser uma farinha in natura, poderá ser utilizada em preparação para crianças desde que seja submetida ao tratamento térmico antes de seu consumo. Na FIAT, o amido pode ter sido degradado apenas parcialmente, mas não ocorreu a sua gelatinização, devido a baixa umidade do grão e o pouco tempo de exposição à temperatura de $150^{\circ} \mathrm{C}$, sendo necessário mais estudos para avaliar a digestibilidade desta farinha. Já o tratamento térmico utilizado para pipocar os grãos (FIAP) foi severo, provocando perdas significativas de proteínas e de aminoácidos essenciais, não sendo, portanto, dentre as farinhas estudadas, a mais recomendada para este público. 
Tabela 3 - Escores químicos das farinhas integrais de grãos de Amaranthus cruentus.

\begin{tabular}{|c|c|c|c|c|c|c|c|c|c|c|}
\hline \multirow{2}{*}{ Farinha } & \multirow{2}{*}{ Idade (anos) } & \multicolumn{9}{|c|}{ Aminoácidos essenciais ----- } \\
\hline & & Phe + Ty r & His & Ile & Leu & Lys & Met + Cys & Thr & Trp & Val \\
\hline \multirow[t]{4}{*}{ FIAI } & 1 a 2 & 1,84 & 1,45 & 1,58 & 0,97 & 1,13 & $0,93^{*}$ & 1,94 & 2,85 & 1,10 \\
\hline & 3 a 10 & 2,07 & 1,64 & 1,58 & 1,01 & 1,22 & $1,00^{*}$ & 2,09 & 2,85 & 1,15 \\
\hline & 11 a 14 & 2,07 & 1,64 & 1,63 & 1,02 & 1,22 & 1,05 & 2,09 & 2,85 & 1,15 \\
\hline & $>18$ & 2,23 & 1,74 & 1,63 & 1,04 & 1,30 & 1,10 & 2,28 & 3,33 & 1,18 \\
\hline \multirow[t]{4}{*}{ FIAC } & 1 a 2 & 1,84 & 1,42 & 1,57 & 0,98 & 1,14 & $0,96^{*}$ & 1,83 & 2,63 & 1,11 \\
\hline & 3 a 10 & 2,07 & 1,60 & 1,57 & 1,01 & 1,23 & 1,04 & 1,97 & 2,63 & 1,17 \\
\hline & 11 a 14 & 2,07 & 1,60 & 1,62 & 1,03 & 1,23 & 1,09 & 1,97 & 2,63 & 1,17 \\
\hline & $>18$ & 2,23 & 1,71 & 1,62 & 1,05 & 1,31 & 1,14 & 2,14 & 3,07 & 1,20 \\
\hline \multirow[t]{4}{*}{ FIAT } & 1 a 2 & 1,89 & 1,41 & 1,63 & 1,02 & 1,05 & $1,00^{*}$ & 1,82 & 2,73 & 1,12 \\
\hline & 3 a 10 & 2,12 & 1,58 & 1,63 & 1,05 & 1,14 & 1,08 & 1,97 & 2,73 & 1,18 \\
\hline & 11 a 14 & 2,12 & 1,58 & 1,69 & 1,07 & 1,14 & 1,13 & 1,97 & 2,73 & 1,18 \\
\hline & $>18$ & 2,28 & 1,69 & 1,69 & 1,09 & 1,22 & 1,18 & 2,14 & 3,19 & 1,21 \\
\hline \multirow[t]{4}{*}{ FIAP } & 1 a 2 & 1,86 & 1,39 & 1,55 & 0,97 & $0,71^{*}$ & 0,94 & 1,96 & 2,79 & 1,09 \\
\hline & 3 a 10 & 2,09 & 1,57 & 1,55 & 1,00 & $0,77^{*}$ & 1,02 & 2,12 & 2,79 & 1,15 \\
\hline & 11 a 14 & 2,09 & 1,57 & 1,60 & 1,02 & $0,77^{*}$ & 1,06 & 2,12 & 2,79 & 1,15 \\
\hline & $>18$ & 2,25 & 1,67 & 1,60 & 1,04 & $0,82^{*}$ & 1,11 & 2,30 & 3,25 & 1,18 \\
\hline
\end{tabular}

*Primeiro aminoácido limitante das farinhas de amaranto em relação às recomendações da WHO/FAO (2007) por faixa etária.

FIAI - farinha integral de grãos de amaranto in natura; FIAC - farinha integral de grãos de amaranto cozidos; FIAT- farinha integral de grãos de amaranto tostados; FIAP - farinha integral de grãos de amaranto pipocados.

\section{CONCLUSÃO}

O cozimento, a tosta e o pipocamento dos grãos de amaranto não afetaram os conteúdos de cinzas e fibra alimentar total, mas alteraram as quantidades de lipídeos, carboidratos e de fibras solúveis e insolúveis.

O processo de pipocamento foi o único que provocou perda significativa de proteína.

Os únicos minerais que apresentaram alterações com o tratamento térmico foram o cobre, na FIAP, com acréscimo de $15,4 \%$ e o cálcio, na FIAT, com acréscimo de $3,1 \%$.

A ingestão diária de $50 \mathrm{~g}$ de uma das farinhas de amaranto produzidas supre mais de $50 \%$ das necessidades em magnésio e ferro de crianças de até 6 anos de idade.

A FIAT e FIAC não apresentam aminoácidos limitantes para indivíduos com idade igual ou superior a 3 anos, de acordo com as recomendações estabelecidas pela WHO/FAO.

Os tratamentos térmicos reduziram os teores de histidina e triptofano do grão in natura, sendo que o pipocamento causou também perdas drásticas de lisina, tornando a FIAP de qualidade inferior as demais farinhas.
Dentre as farinhas produzidas, destaca-se a FIAT, por produzir farinha com teores de proteínas, lipídios e perfil aminoacídico iguais a FIAC e ser de obtenção mais simples e mais rápida.

\section{REFERÊNCIAS}

AMAYA-FARFAN, A. et al. A proposta do amaranto. Segurança Alimentar e Nutricional, v.12, n.1, p.47-56, 2005.

AMERICAN ASSOCIATION OF CEREAL CHEMISTIS (AACC). Approved methods of analysis. 11.ed. St Paul, MN, 1999. (Method 32-07.01. Soluble, Insoluble, and Total Dietary Fiber in Foods and Food Products).

ASSOCIATION OF OFFICIAL ANALYTICAL CHEMISTS (AOAC). HORWITZ, W. (Ed). Official methods of analysis the association of chemistry. 16 ed. Arlington, Washington, D.C., 1999. 1298p.

BASSINELlO, P. Z.; ROCHA, M. S.; COBUCCI, R. M. A. Avaliação de diferentes métodos de cocção de arroz de terras altas para teste sensorial. Embrapa Arroz e Feijão, 2004. (Embrapa Arroz e Feijão. Comunicado Técnico, 84).

BEJOSANO, F.P.; CORKE, H. Protein quality evolution of amaranthus wholemeal flours and protein concentrates. J. Sci. Food Agr., v.76, n.1, p.100-106, 1998.

BELCHIOR, E.B. et al. Avaliação dos impactos do uso do gesso agrícola na cultura da soja em algumas áreas de cerrado. 
Empresa Brasileira de Pesquisa Agropecuária. 2010. 35p. (Documentos 297).

BIANCHINI, M.G.A.; BELÉIA, A.D.P. Umidade e congelamento de grãos de amaranto e sua capacidade de expansão térmica. Pesqui. Agropecu. Bras., v.45, n.8, p.917-924, 2010. Disponível em: $<$ http://seer.sct.embrapa. br/index.php/pab/article/view/7940>. Acesso em 20/jan/2013.

BRASIL, Ministério da Saúde. Portaria n.685, de 27/08/1998. Princípios gerais para estabelecimento níveis máximos contaminantes químicos em alimentos. Disponível em: $<\mathrm{http}: / /$ portal.anvisa.gov.br/wps/wcm/connect/8c494f804745801a8c00dc $3 \mathrm{fbc} 4 \mathrm{c} 6735 / \mathrm{PORTARIA}+\mathrm{N}+\% \mathrm{C} 2 \% \mathrm{BA}+685,+\mathrm{DE}+27+\mathrm{DE}+\mathrm{AGO}$ $\mathrm{STO}+\mathrm{DE}+1998$.pdf?MOD=AJPERES $>$. Acesso em 20/jan/2013.

BRASIL, ANVISA (AGÊNCIA NACIONAL DE VIGILÂNCIA SANITÁRIA). RDC n.269, de 22 de setembro de 2005. Regulamento técnico sobre a ingestão diária recomendada (IDR) de proteína, vitaminas e minerais. Disponível em: $<\mathrm{http}: /$ portal.anvisa.gov. br/wps/wcm/connect/1884970047457811857dd53fbc4c6735/ RDC_269_2005.pdf?MOD=AJPERES: $>$. Acesso em 20/jan/2013.

CAPRILES, V.D. et al. Effects of processing methods on amaranth starch digestibility and predicted glycemic index. J Food Sci, v.73, n.7, p.H161-H164, 2008. Disponível em: <http://onlinelibrary. wiley.com/doi/10.1111/j.1750-3841.2008.00869.x/pdf>. Acesso em jan. 2012 doi: 10.1111/j.1750-3841.2008.00869.x.

COLUCCI, A.C.A. Consumo alimentar da população brasileira: evolução nos últimos anos. Science \& Nutrition, v.4, p.1-20, 2010

FERREIRA, T.A.P.C. et al. Características nutricionais e funcionais do amaranto (Amaranthus spp.). J. Brazilian Soc. Food Nutr., v.32, n.2, p.91-116, 2007.

GAMEL, T.H. et al. Nutritional study of raw and popped seed protein of Amaranthus caudadus L and Amaranthus cruentus L. J. Sci. Food Agr., v.84, p.1153-1158, 2004. doi: 10.1002/jsfa.1781.

GAMEL, T.H. et al. Effect of seed treatments on the chemical composition of two amaranth species: oil, sugars, fibres, minerals and vitamins. Journal of the Science of Food and Agriculture, v.86, p.82-89, 2006. doi: 10.1002/jsfa.2318.

HAGEN, S. R.; FROST, B.; AUGUSTIN, J. Pre-column Phenylisothiocyanate derivatization and Liquid-Chromatography of Aminoacids in Food. J. Assoc. Off. Ana. Chem., v. 72, n. 6, p. 912-916, nov./dez., 1989.

INSTITUTO ADOLFO LUTZ -IAL. Métodos físico-químicos para análise de alimentos: normas analíticas do Instituto Adolfo Lutz. 4. ed., 2005. 1018p.

MBURU, M.W. et al. Properties of a complementary food based on amaranth grain (Amaranthus cruentus) grown in Kenya. J. Agr. Food Technol., v.1, n.9, p.153-178, 2011. Disponível em: <http:// www.textroad.com/pdf/JAFT/J.\%20Agric.\%20Food.\%20Tech.,\% 201(9)153-178,\%202011.pdf>. Acesso em jan. 2013.

IRVING, D. W.; BETSCHART, A. A.; SAUNDERS, R. M. Morphological studies on Amaranthus cruentus. J. Food Sci. v.46, n.4, p. $1170-1174.1981$.
MENDONÇA, S. et al. Amaranth protein presents cholesterollowering effects. Food Chem., v.116, p.738-742, 2009 Disponível em: <http://www.sciencedirect.com/science/article/ pii/ S0308814609003161>. Acesso em fev. 2012. doi:10.1016/j. foodchem.2009.03.021.

REPO-CARRASCO-VALENCIA, R. et al. Dietary fiber and other functional components in two varieties of crude and extruded kiwicha (Amaranthus caudatus). J. Cereal Sci., v.49, p.219224, 2009. Disponível em: <http://www.sciencedirect.com/ science/article/pii /S0733521008001689>. Acesso em nov. 2011. doi:10.1016/j.jcs.2008.10.003.

RODAS, B.; BRESSANI, R. Contenido de aceite, ácidos grasos y escualeno en variedades crudas y procesadas de grano de amaranto. Archivos Latinoamericanos de Nutrición2, v. 59, n. 1, p. 82-87, 2009. <http://www.alanrevista.org/ediciones/2009-1/pdf/aceite acidos_grasos_escualeno_en_variedades_grano_amaranto.pdf $>$. Acesso em fev/2013.

ROY, R.N. et al. Plant nutrition for food security: a guide for integrated nutrient management: Fertilizer and plant nutrition. FAO, 2006. (Bulletin n.16).

SCHNETZLER, K.A.; BREENE, W.M. Food uses and amaranth products research: a comprehensive review. In: . PAREDESLÓPEZ, O. (Ed). Amaranth: biology, chemistry, and technology. Boca Raton: CRC, 1994. p.155-184.

SEGURA, M.E.B.; BRESSANI, R. Distribución de la proteína em fracciones físicas de La molienda y tamizado del grano de amaranto. Arch. Latinoam. Nutr., v.52, n.2, p.167-171, 2002.

SPEHAR, C.R. et al. Amaranth BRS Alegria: alternativa para diversificar os sistemas de produção. Pesqui. Agropecu. Bras., v.38, n.5, p.659-663, 2003.

SPIES, J. R. Determination of tryptophan in proteins. Anal. Chem., v.39, p.1412-1415, 1967.

UNITED STATES FOOD AND DRUG ADMINISTRATION. FDA provides guidance on 'whole grain' for manufacturers. Fevereiro, 2006. Disponível em: <www.fda.gov/bbs/topics/ news/2006NEW01317html>. Acesso em: 15/fev/ 2010.

VIEIRA, C.R. et al. Composição centesimal e conteúdo de aminoácidos, ácidos graxos e minerais de seis cultivares de soja destinadas à alimentação humana. Pesqui. Agropecu. Bras., v.34, n.7, p.1277-1283, 1999. Disponível em: <http://www.scielo.br/ pdf/pab/v34n7/8217.pdf>. Acesso em: 15/fev/ 2010

WALTER, M. et al. Arroz: composição e características nutricionais. Ciência Rural, v.38, n.4, p. 1184-1192, 2008.

WHITE, J. A.; HART, R. J.; FRY, J. C. An evaluation of the waters Pico-Tag System for the aminoacids analysis of food materials. $\mathbf{J}$. Automatic Chem., v. 8, n.4, p. 170-177, Oct-Dec., 1986.

WORLD HEALTH ORGANIZATION. Protein and amino acid requeriments in human nutrition. Report of a Joint WHO/FAO/ UNU Expert Consultation. OMS, 2007. 284p. (WHO technical report series n.935). 